TI 2017-100/VII

Tinbergen Institute Discussion Paper

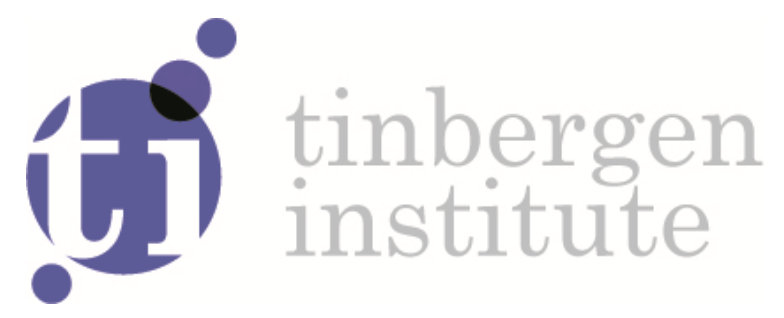

Intuitive versus Contemplative: Do

Entrepreneurs differ in their DecisionMaking Style from Managers and Employees?

Martin Koudstaal ${ }^{1}$

Randolph (R.) Sloof ${ }^{2}$

Mirjam (C.M.) van Praag ${ }^{3}$

1: Rabobank

2: UvA; Tinbergen Institute, The Netherlands

3: Copenhagen Business School 
Tinbergen Institute is the graduate school and research institute in economics of Erasmus University Rotterdam, the University of Amsterdam and VU University Amsterdam.

Contact: discussionpapers@tinbergen.nl

More TI discussion papers can be downloaded at the Tinbergen Site

Tinbergen Institute has two locations:

Tinbergen Institute Amsterdam

Gustav Mahlerplein 117

1082 MS Amsterdam

The Netherlands

Tel.: +31(0)20 5984580

Tinbergen Institute Rotterdam

Burg. Oudlaan 50

3062 PA Rotterdam

The Netherlands

Tel.: +31(0)10408 8900 


\title{
Intuitive versus Contemplative: Do Entrepreneurs differ in their Decision-Making Style from Managers and Employees?
}

\author{
Martin Koudstaal \\ Rabobank, New York City \\ Randolph Sloof \\ University of Amsterdam (UvA) and Tinbergen Institute (TI) \\ Mirjam van Praag \\ Copenhagen Business School, UvA, CEPR, IZA and TI
}

October 16, 2017

\begin{abstract}
We examine in a large survey $(n=1,928)$ how contemplative entrepreneurs, managers and employees are in their decision making styles. Besides two well-known subjective measures taken from psychology, we also build on Rubinstein (2016) by including two objective measures derived from response times and the nature of the strategic choices made. Supporting conventional wisdom, we find that entrepreneurs have a stronger subjective Faith in Intuition than others. Their actual action choices are partly in line with this: entrepreneurs make indeed more intuitive choices than managers, but are equally intuitive as employees. At the same time entrepreneurs have response times and a subjective Need for Cognition that (on average) equal those of managers. Together these findings tentatively suggest that entrepreneurs start from a stronger prior intuition, making them ceteris paribus more intuitive than others, but at the same time share with managers a higher need for cognition, and thus take more time to think things over.
\end{abstract}

Key words: Response times, contemplativeness, faith in intuition, need for cognition, entrepreneurs, managers, lab-in-the-field experiment.

JEL codes: L26, C93, D03, M13.

\section{Introduction}

People differ in the way they make strategic decisions. Some primarily follow their "gut" feeling and decide based on their intuition what seems best. Others, in contrast, prefer to think things over and rely on strategic reasoning before they take a decision. Entrepreneurs are typically thought of belonging to the more intuitive type. Given the uncertainty of their business environment and the limited availability of useful information, entrepreneurs may lean more on decision making heuristics 
than other strategic decision makers, like managers, do. Grasping windows of opportunities may also preclude them from more contemplative decision making, under which first more information is gathered before a decision is taken. Focusing on the willingness to generalize from a limited number of observations, Busenitz and Barney (1997) indeed find that entrepreneurs are more likely to use this representativeness heuristic than managers in large organizations do. Yet in other instances entrepreneurs are less biased than other strategic decision makers; Burmeister and Schade (2007) for instance find that entrepreneurs are less succeptible to a status quo bias (i.e. selecting previously chosen alternatives too often) than start up bankers are (but equally affected as students). ${ }^{1}$

In a recent paper, Rubinstein (2016) proposes a typology of strategic decision makers based on their observed action choices. People are confronted with various strategic situations (games), which all have actions that are considered instinctive and actions that are seen as more contemplative. The classification of actions is based on (average) response times, with the fast actions being the instinctive ones and the slow actions the more contemplative ones. Rubinstein's typology thus allows for an objective assessment of decision making styles based on actual choice behavior and response times. The binary distinction between fast and slow thinking has been part of various dual-process theories developed within psychology as well (see e.g. Evans, 2008 for a review). While these theories come in different forms, they all have in common that one processing mechanism (System 1 ) is fast, non-conscious and intuitive, while the other (System 2) is slow, controlled and concious. (The bestseller "Thinking, fast and slow" by Kahneman (2011) provides a popular discussion of the two systems approach.) One example is given by the Cognitive-Experiential Self-Theory (CEST) of Epstein (2003), which portrays two independently operating systems: the "intuitive-experiential system" and the "analytical-rational system". These two decision making styles have been extensively studied empirically, mainly using the Faith in Intuition (FI) and Need for Cognition (NFC) scales of Epstein et al. (1996) which are based on subjective self-assesments.

The aim of this paper is to thoroughly verify conventional wisdom that entrepreneurs have a decision making style that differs from others, notably managers. In doing so, we believe that our paper offers two contributions. First, we expand on Rubinstein (2007, 2013, 2016) by investigating his typology among large samples of established entrepreneurs, managers and employees $(\mathrm{n}=1,928)$, hence those people who actively participate in the labor market. Second, we test the consistency of the results on the two sets of measures. In other words, do the 'objective' measures based on choice behavior and response times lead to similar results as the 'subjective' measures Faith in Intuition and Need for Cognition do?

Our findings show that entrepreneurs make significantly more intuitive choices than managers do, but not than employees. At the same time entrepreneurs share with managers a higher response time than employees. For the subjective measures we find that entrepreneurs have a significantly higher score on Faith in Intuition than all others, while managers have the highest score on Need for Cognition (with entrepreneurs in between employees and managers). A potential explanation

\footnotetext{
${ }^{1}$ See Hsu et al. (2017) and Kraus et al. (2016) for recent reviews of experimental studies in entrepreneurship. Shepherd et al. (2015) provide a broad review of the literature on entrepreneurial decision making.
} 
for these seemingly mixed findings on the objective and the subjective measures might be that entrepreneurs start from a stronger intuitive prior, but share with managers a higher need for cognition and (on average) take more time to think. Moreover, entrepreneurs and managers also seem to use their time in a more effective way than employees do. In particular, in a regression framework, we see that an individual's CI score (dependent variable) varies more strongly with response time (included as one of the explanatory variables) for entrepreneurs and managers than for employees (i.e., an estimated positive coefficient of a larger size).

The remainder of this paper is organized as follows. The next section discusses our design choices regarding measurement and sampling. Empirical findings are reported in Section 3. The final section concludes. .

\section{Measurement and sampling}

\subsection{Objective measures of decision-making styles}

For our objective measures we rely on response times and the Contemplative Index (CI) as proposed by Rubinstein (2016). Rubinstein uses ten strategic games which all have intuitive actions (coded 0 ) and contemplative ones (coded 1). The distinction is based on the response time of subjects that chose the action being (on average) below or above the median response time of all subjects who played the games. Fast actions are thus the more intuitive ones, slow actions the more contemplative ones. $^{2}$ The CI index equals the number of times (out of overall 10 games) a contemplative action is chosen. Rubinstein (2016) finds that the index has predictive power when examining subjects' behavior in other games than the ten used for the construction of the CI.

We would have liked to include all ten games of Rubinstein (2016) in our survey. However, the nature of our subject pool (working participants) required that we kept it short (including all 10 games in the survey would have led to response times of over 12 minutes only for the games). We therefore selected three games that arguably could serve as a decent proxy for the CI. ${ }^{3}$ In selecting them we used the following five criteria: i) the game setup remains close to the entrepreneur / manager world, ii) the game can be well-understood in an online survey, iii) the game can be played in a relatively short period of time, iv) the game clearly differentiates between intuitive and contemplative thinkers, and v) the game contains no obvious confounding factors. Applying these criteria, we ultimately chose to include the three games listed below (where the descriptions of the strategic situation are taken literally from Rubinstein (2016)). For convenience we have marked the intuitive choices with an (I) and the contemplative ones with a (C). In line with Rubinstein (2016), we also recorded the response times for each participant on each of these three games. ${ }^{4}$

\footnotetext{
${ }^{2}$ To further strengthen his case, Rubinstein (2016) also tested for agreement rates about the intuitive and contemplative choices among 17 graduate students who served as raters.

${ }^{3}$ Initially we had four games in our original survey, but decided to drop one of the games ("Relying on an other player's rationality") based on the updated version of Rubinstein (2016). There he reports that the agreement rate about the intuitive and contemplative choice among the 17 graduate students is low for this particular game.

${ }^{4}$ Response time is measured as the time between opening the decision screen and the time the OK button is clicked
} 


\section{\#1: The One-shot Chain Store Game}

In your neighborhood, there is one grocery store and one tailor. At the moment, the profits of the grocery store owner are around $\$ 120,000$ per year while the tailor's profits are only $\$ 50,000$ per year. The tailor asks your advice about whether to change his shop into a grocery store. He figures that if the grocer does not respond aggressively to the new competition, each of them will earn about $\$ 70,000$ per year. On the other hand, if the grocer does respond aggressively and starts a price war, then the earnings of each store will be reduced to about $\$ 25,000$ per year. What is your advice to the tailor? [ENTER (C) or NOT ENTER (I)].

\section{\#2: Hotelling's Main Street Game}

Imagine you are the manager of a chain of cafes competing with two other similar chains. Each of you is about to rent a shop in one of the 7 new identical huge apartment buildings standing along a beach strip. Once each of you knows exactly where the other two competitors locate it will be too late to move to another location. You expect that the customers (the residents in the 7 buildings) will not distinguish between the three cafes and will pick the one which is closest to their home. In which building (a number between 1 and 7) will you locate your cafe? [1 (I), 2 (C), 3 (C), 4 (I), 5 (C), $6(\mathrm{C})$ or 7 (I)].

\section{\#3: The Two-contests Game}

Imagine you are participating in a game with over 200 participants worldwide. Each participant chooses to compete in one of two contests. In contest $\mathrm{A}$, each contestant guesses the outcomes of 20 coin flips (heads or tails). In contest B, each contestant guesses the outcomes of 20 rolls of a die (i.e., each of the twenty guesses is a number 1, 2, 3, 4, 5 or 6). Each contest will be conducted independently. In each contest, you will be competing against people who, like you, chose that contest. After the guesses of all the participants are collected, a computer will simulate a series of 20 coin flips for contest A and a series of 20 rolls of a die for contest B. The winner of each contest will be the person with the most correct guesses. (In the case of a tie, the winner will be chosen by a lottery among those with the most correct guesses.) I choose to participate in: [CONTEST A (I) or CONTEST B (C)].

\subsection{Subjective measures of decision-making styles}

Our subjective measures are taken from Epstein et al. (1996), who construct a Rational-Experiental Inventory based on Cognitive-Experiential Self-Theory (Epstein, 2003). It distuiguishes between two cognitive styles: the intuitive-experiential style, as measured by Faith in Intuition (FI), and the analytical-rational style, as measured by Need for Cognition (NFC). We use the short form of the Rational-Experiental Inventory to assess these two styles, which consists of the following 10 items:

\section{Faith in Intuition (FI)}

- I trust my initial feelings about people.

- I believe in trusting my hunches.

- My initial impressions of people are almost always right.

to confirms one's choice. As Cappelen et al. (2016) note, the overall response time is the sum of time spent on reading and understanding the decision problem, time spent on deliberating, and the time taken to implement the decision. As such it is an imperfect measure of deliberation time. 
- When it comes to trusting people, I can usually rely on my "gut feelings".

- I can usually feel when a person is right or wrong even if I can't explain how I know.

\section{Need for Cognition (NFC)}

- I don't like to have to do a lot of thinking. (R)

- I try to avoid situations that require thinking in depth about something. (R)

- I prefer to do something that challenges my thinking abilities rather than something that

requires little thought.

- I prefer complex to simple problems.

- Thinking hard and for a long time about something gives me little satisfaction.

All 10 items were rated on a 5-point Likert scale ranging from "Strongly disagree" to "Strongly agree". With the exception of the reversely scored items indicated by (R), "Strongly disagree" was assigned 1 point, "Disagree" 2 points, "Neutral" 3 points, "Agree" 4 points, and "Strongly agree" 5 points. To obtain overall scores for FI and NFC, all relevant individual scores were added up. Hence, the maximum (minimum) scores for both FI and NFC were 25 (5).

\subsection{Sampling}

Our sampling procedure was similar to Koudstaal et al. (2016) and we collaborated with the same business partners as reported there. ${ }^{5}$ The survey included a part consisting of the selected games from Rubinstein (2016) as well as a part asking participants to what extent they agreed with the ten statements related to Faith in Intuition and Need for Cognition. As the payment for these two parts did no vary with the choices made, these choices could be considered hypothetical (in line with Rubinstein, 2016). ${ }^{6}$

Invitations to participate were sent to around 15,000 entrepreneurs, 4,000 managers and 8,000 employees on December $16^{\text {th }}, 2014$. All participants had 14 days to respond and a reminder was sent after 7 days. The survey was completed by 696 entrepreneurs, 265 managers and 967 employees $(n=1,928)$. Response rates were thus between $5-15 \%$, in line with earlier experiences. Occupational groups were defined as in Koudstaal et al. (2016). Entrepreneurs are those who have founded, inherited or taken over a company that they are currently (co-) managing. Also individuals who obtained firm ownership over a company within 5 years after start-up and who are currently its

\footnotetext{
${ }^{5}$ In fact, we combined the present survey on decision-making styles with a number of incentivized items on loss aversion that we needed for a robustness check of our first study on risk attitudes. The overall survey contained four parts. Parts one (high stakes lotteries with mixed prospects) and four (WTP/WTA for a fancy bread tray) measured loss aversion in various ways and are reported upon in Section 4.3 of Koudstaal et al. (2016). Part two consisted of the Rubinstein games and part 3 contained the FI and NFC statements studied here. Compared to the sample of $n=1931$ participants reported in our prveious study, we lose 3 participants for which Response Time is missing.

${ }^{6}$ Before filling out each of these two parts, participants were informed that they would receive $€ 200$ in their accounts after completing the Rubinstein games and $€ 175$ upon completion of the part with the subjective FI and NFC statements. We included this element to ensure that participants could actually lose money in the incentivized choices in Parts 1 and 4. Instead of paying out every participant, we opted to pay out 20 randomly drawn prize winners. For these prize winners, we added up all gains and losses in Parts 1 and 4 and added the €375 gained in Parts 2 and 3 to determine the overall earnings.
} 
(co-)manager were classified as entrepreneur. A manager was someone who had at least two direct reporting lines in an organization that was not started up by him/herself. Project managers who have overall responsibility for their projects and at least two direct reporting lines were also considered as managers. Employees were those who were employed by an organization but not belonging to the other two categories.

\section{Empirical findings}

\subsection{Descriptive statistics}

Panel A in Table 1 displays the sample descriptive statistics of both the objective and the subjective measures of decision-making styles. The total number of contemplative choices reported in the first row reveal that most individuals in our sample choose rather intuitively. Participants on average make 0.87 contemplative choices in the three games, while the median equals 1 out of 3 . The average response time is close to 200 seconds, thus slightly more than one minute per game. Note though that there is large variation in response times; the standard deviation equals $135 \mathrm{~s}$. The bottom two rows of Panel A show that the average values for Faith in Intuition and Need for Cognition are 18.92 and 17.74 , respectively (where the feasible range is 5 to 25 ).

Table 1 Descriptive Statistics Decision Making Style

\begin{tabular}{|c|c|c|c|c|c|c|}
\hline Panel A: Means & Obs. & Mean & Median & St. dev. & Min. & Max. \\
\hline \multicolumn{7}{|l|}{ Objective measures } \\
\hline - Contemplative Index (CI) & 1,928 & 0.87 & 1 & 0.82 & 0 & 3 \\
\hline - Response Time (RT) & 1,928 & $197.14 \mathrm{~s}$ & $163.15 \mathrm{~s}$ & $134.56 \mathrm{~s}$ & $8.84 \mathrm{~s}$ & $1,406.19 \mathrm{~s}$ \\
\hline \multicolumn{7}{|l|}{ Subjective measures } \\
\hline - Faith in Intuition (FI) & 1,928 & 18.92 & 19 & 2.78 & 7 & 25 \\
\hline - Need for Cognition (NFC) & 1,928 & 17.74 & 18 & 3.09 & 7 & 25 \\
\hline Panel B: Correlations & & & & CI & $\mathrm{RT}$ & FI \\
\hline \multicolumn{7}{|l|}{ Objective measures } \\
\hline - Contemplative Index (CI) & & & & - & & \\
\hline - Response Time (RT) & & & & $0.14 * * *$ & - & \\
\hline \multicolumn{7}{|l|}{ Subjective measures } \\
\hline - Faith in Intuition (FI) & & & & $-0.05 * *$ & $-0.08 * * *$ & - \\
\hline - Need for Cognition (NFC) & & & & $0.08 * * *$ & $0.11 * * *$ & $-0.12 * * *$ \\
\hline
\end{tabular}


Panel B reports the (Pearson) correlations between the four measures. In line with Rubinstein (2016), we find that response times are positively associated with contemplative thinking. Equally predictable, we also find that a higher score on Faith in Intuition is negatively associated with the Contemplative Index (CI) and response times, while the reverse holds for Need for Cognition. Consistent with this pattern, Faith in Intuition and Need for Cognition are negatively correlated.

In Table 2 we report some background characteristics of our sample. In line withKoudstaal et al. (2016), we find that entrepreneurs and managers are on average quite comparable to each other, while employees are somewhat younger and more likely to be female. On average, employees also have a lower degree of education and are less likely to have an Economics (educational) background.

Table 2 Background Characteristics of Entrepreneurs, Managers, and Employees

\begin{tabular}{lccc}
\hline & $\begin{array}{c}\text { Entrepreneurs } \\
(n=696)\end{array}$ & $\begin{array}{c}\text { Managers } \\
(n=265)\end{array}$ & $\begin{array}{c}\text { Employees } \\
(n=967)\end{array}$ \\
\hline Age & $49.11^{\mathrm{a}, \mathrm{b}}$ & $47.22^{\mathrm{b}, \mathrm{c}}$ & $43.88^{\mathrm{a}, \mathrm{c}}$ \\
Female (dummy) & $0.28^{\mathrm{a}}$ & $0.32^{\mathrm{c}}$ & $0.44^{\mathrm{a} . \mathrm{c}}$ \\
Education (highest degree): & $\mathrm{a}, \mathrm{b}$ & $\mathrm{b}, \mathrm{c}$ & a,c \\
- High school & $5 \%$ & $2 \%$ & $10 \%$ \\
- Lower vocational degree & $14 \%$ & $4 \%$ & $33 \%$ \\
- College education & $46 \%$ & $42 \%$ & $38 \%$ \\
- University education & $35 \%$ & $52 \%$ & $19 \%$ \\
Econ (dummy) & $0.22 \mathrm{a}$ & $0.24 \mathrm{c}$ & 0.12 a,c \\
& & & \\
\hline
\end{tabular}

Notes: Letter subscripts indicate significant differences between two occopational groups at the 5\% level (a for entrepreneurs versus employees, b for entrepreneurs versus managers, and c for managers versus employees); for age, female and Econ using a two sided t-test and for Education a Chi-Squared test.

\subsection{Differences between occupational groups}

Table 3 reports the raw differences between entrepreneurs, managers and employees. Entrepreneurs appear to make significantly less contemplative choices than managers (0.84 vs. 1.04) do, but equally so as employees (0.84). Somewhat surprisingly, the raw differences in response times do not fully match the findings on the Contemplative Index. Managers have a significantly higher response time than employees, as expected, but we also find that the same holds true for entrepreneurs vis-à-vis employees. In fact, entrepreneurs and managers do not differ in this regard. We will return to these seemingly mixed findings for the CI index and response times in the next subsection. 
Table 3 Raw Differences in Decision Making Styles between Occupational Groups

\begin{tabular}{|c|c|c|c|c|}
\hline & $\begin{array}{l}\text { Entrepreneurs } \\
\quad(n=696)\end{array}$ & $\begin{array}{l}\text { Managers } \\
(n=265)\end{array}$ & $\begin{array}{c}\text { Employees } \\
(n=967)\end{array}$ & $\begin{array}{c}\mathrm{p} \text { value of } \\
\text { ANOVA test }\end{array}$ \\
\hline \multicolumn{5}{|l|}{ Objective measures } \\
\hline - Contemplative Index (CI) & $0.84^{\mathrm{b}}$ & $1.04 \mathrm{~b}, \mathrm{c}$ & $0.84^{\mathrm{c}}$ & $<0.01$ \\
\hline - Response Time (RT) & $210.14 \mathrm{~s}^{\mathrm{a}}$ & $209.99 \mathrm{~s}^{\mathrm{c}}$ & $184.25 \mathrm{~s}^{\mathrm{a}, \mathrm{c}}$ & $<0.01$ \\
\hline \multicolumn{5}{|l|}{ Subjective measures } \\
\hline - Faith in Intuition (FI) & 19.12 b & $18.61 \mathrm{~b}$ & 18.87 & 0.03 \\
\hline - Need for Cognition (NFC) & $17.93^{\mathrm{a}, \mathrm{b}}$ & $18.55^{\mathrm{b}, \mathrm{c}}$ & $17.38^{\mathrm{a}, \mathrm{c}}$ & $<0.01$ \\
\hline
\end{tabular}

Notes: Letter subscripts indicate significant differences between two occopational groups at the $5 \%$ level using a two sided t-test ( $a$ for entrepreneurs versus employees, b for entrepreneurs versus managers, and c for managers versus employees). The final column reports the p-value of an ANOVA test comparing all three occupational groups at the same time.

The results for the subjective measures show that entrepreneurs have the highest Faith in Intuition, followed by employees and managers (who do not differ from each other). On the Need for Cognition scale, managers score highest, followed by entrepreneurs and then employees.

Table 3 reports raw differences, but does not take differences in background characteristics into account. It is however important to do so, as entrepreneurs and managers are typically better educated and more likely to be male than employees, see Table 2 . We therefore next consider the occupational differences in a regression framework. Table 4 depicts the results when running ordered probit regressions on the four different measures of decision-making styles (for response time we perform regular regressions). Column (1a) first confirms that entrepreneurs and employees are indeed equally intuitive, while managers are more contemplative if background characteristics are left out. Adding controls in Column (1b) does not change this result; the coefficient of the "Manager" dummy is somewhat lower, but still significant at the $5 \%$ level. Furthermore, we also find that younger, male, and higher educated participants tend to behave more contemplative (in line with e.g. Choi et al., 2014), while having Economics as the field of study does not have a significant effect. ${ }^{7}$

\footnotetext{
${ }^{7}$ We included the dummy variable "Econ" to control for the possibility that these participants might have been somewhat more familiar with the strategic games than others.
} 
Table 4 Ordered Probit Regressions on Decision-Making Styles of Occupational Groups

\begin{tabular}{|c|c|c|c|c|c|c|c|c|}
\hline \multirow[b]{3}{*}{ Dep. variable: } & \multicolumn{4}{|c|}{ Objective measures } & \multicolumn{4}{|c|}{ Subjective measures } \\
\hline & (1a) & (1b) & (2a) & $(2 \mathrm{~b})$ & (3a) & $(3 b)$ & (4a) & $(4 b)$ \\
\hline & $\mathrm{CI}$ & $\mathrm{CI}$ & $\mathrm{RT}$ & $\mathrm{RT}$ & FI & FI & NFC & NFC \\
\hline \multirow[t]{2}{*}{ Entrepreneur } & -0.002 & -0.022 & $25.886^{* * *}$ & $16.286^{* *}$ & $0.089^{*}$ & $0.189^{* * *}$ & $0.183^{* * *}$ & 0.065 \\
\hline & {$[0.054]$} & {$[0.060]$} & {$[6.862]$} & {$[7.575]$} & {$[0.050]$} & {$[0.054]$} & {$[0.050]$} & {$[0.055]$} \\
\hline \multirow[t]{2}{*}{ Manager } & $0.254^{* * *}$ & $0.202^{* *}$ & $25.741^{* * *}$ & 13.651 & -0.089 & 0.018 & $0.383^{* * *}$ & $0.156^{* *}$ \\
\hline & {$[0.077]$} & {$[0.082]$} & {$[9.028]$} & [9.781] & {$[0.070]$} & {$[0.074]$} & {$[0.067]$} & {$[0.071]$} \\
\hline \multirow[t]{2}{*}{ Age / 10} & & $-0.086^{* * *}$ & & 0.457 & & $-0.047^{* *}$ & & $-0.084^{* * *}$ \\
\hline & & {$[0.024]$} & & {$[2.994]$} & & {$[0.022]$} & & {$[0.021]$} \\
\hline \multirow[t]{2}{*}{ Female } & & $-0.172^{* * *}$ & & $-18.738^{* * *}$ & & $0.275^{* * *}$ & & $-0.169^{* * *}$ \\
\hline & & {$[0.053]$} & & [6.364] & & {$[0.049]$} & & {$[0.049]$} \\
\hline \multirow[t]{2}{*}{ Education } & & $0.074^{* *}$ & & $8.034^{* *}$ & & $-0.095^{* * *}$ & & $0.319^{* * *}$ \\
\hline & & {$[0.031]$} & & {$[3.797]$} & & {$[0.027]$} & & {$[0.028]$} \\
\hline \multirow[t]{2}{*}{ Econ } & & 0.031 & & $26.266^{* * *}$ & & $0.143^{* *}$ & & -0.038 \\
\hline & & {$[0.068]$} & & {$[10.106]$} & & {$[0.065]$} & & {$[0.060]$} \\
\hline Obs. & 1,928 & 1,928 & 1,928 & 1,928 & 1,928 & 1,928 & 1,928 & 1,928 \\
\hline Log lik. & $-2,223$ & $-2,205$ & $-12,177$ & -12163 & -4596 & -4572 & -4858 & -4770 \\
\hline $\mathrm{ENT}=\mathrm{MAN}$ & $<0.01$ & $<0.01$ & 0.99 & 0.79 & 0.02 & 0.02 & $<0.01$ & 0.21 \\
\hline
\end{tabular}

Notes: Age is divided by 10 for presentational purposes. The categorical variable 'education' has been summarized into one variable instead of using a set of dummies. The education variable takes on the value 0 if the highest attained level is high school or lower, 1 if secondary education is obtained at a higher level, 2 if a participant has college education and 3 if the participant has a university degree. Econ is an indicator variable which is 1 if the field of study was Economics. Significance at the $10 \%$ level is denoted by $*, 5 \%$ by ${ }^{* *}$, and $1 \%$ by $* * *$, with robust standard errors reported in square brackets. The final row reports the p-value of a Wald test that 'Entrepreneur' = 'Manager'.

Columns (2a) and (2b) report the results for response time as the dependent variable (using standard regressions). Just as in Table 3, Column (2a) illustrates that entrepreneurs and managers have a significantly higher response time than employees. However, with controls these differences become smaller. The occupational differences appear partly driven by background characteristics like gender, education and field of study. Nevertheless, with controls the Entrepreneur dummy remains significant. The Manager dummy is no longer significant but, as the final row shows, it can also not be rejected that entrpreneurs and managers are equal. ${ }^{8}$ Occupation per se thus appears one of the drivers of differences in response time. The last two sets of columns relate to Faith in Intuition and Need for Cognititon. In line with the raw differences in Table 3, Column (3a) indicates that entrepreneurs have the highest Faith in Intuition, while Column (4a) shows that managers stand out in their Need for Cognition (with entrepreneurs in between). When we include

\footnotetext{
${ }^{8} \mathrm{~A}$ Wald test that both dummies (Entrepreneur and Manager) equal zero at the same time yields $p=0.08$.
} 
background characteristics in Columns (3b) and (4b), these results keep standing. We only find that the difference between entrepreneurs and managers on Need for Cognition is no longer significant (p-value is 0.21 ).

Overall the following picture emerges. Entrepreneurs make more intuitive choices than managers do, but are equally intuitive as employees. At the same time the response time of entrepreneurs equals those of managers, both taking more time than employees. Entrepreneurs also subjectively report a stronger faith in intution than managers and employees have, but share a stronger need for cognition with managers that is larger than those of employees. The next subsection explores how to reconcile these findings.

\subsection{Prior intuition and the effect of taking more time}

The games selected by Rubinstein (2016) all share the common feature that the instinctive choice(s) a person a priori is inclined to make differs from the complementative choice(s) that one would more likely make after taking sufficient time to think the decision over. However, besides different choices directly resulting from deciding either fast or slow, people may also differ in the strength of their prior intution, i.e. the inclination to choose the intuitive option when response times are low, as well as the amount of time it takes to realize that one's prior intuition might perhaps be misguided. (Simply put, people who take an equal amount of time may still make different choices.) In this subsection we explore whether this may potentially provide an explanation for the seemingly mixed finding that entrepreneurs make more intuitive choices than managers, but on average have equal response times. And similarly so for the observation that entrepreneurs are equally intuitive in their choices as employees, while at the same time take more time to think. In particular, a potential explanation for these findings might be that entrepreneurs start from a stronger prior intuition, making them ceteris paribus more intuitive than others, but at the same time share with managers a higher need for cognition, and therefore take more time to think than employees (bringing them close(r) to employees again in terms of intuitive choices).

Table 5 provides some suggestive evidence in this regard. It is constructed by first ranking all participants from quickest to slowest in terms of response times. The quickest (bottom) $25 \%$ and the slowest (top) $25 \%$ are subsequently seperated from the rest (25-75\%). For each of these three response time classes the table reports the average CI score per occupational category, together with the percentage of participants from that occupational category within that class. Row-wise (i.e. for each occupational category and overall) percentages add up to 100\%. As expected, the average CI score increases moving from the quickest $25 \%$ to the slowest $25 \%$, irrespective of occupational category. Focusing on the quickest $25 \%$, the entrepreneurs within this class have a significantly lower CI score and thus make significantly more intuitive choices than managers do; at the $10 \%$ level this also holds true for the comparison with employees. Assuming that people within this class have to rely strongly on their "gut feeling", this arguably suggests that entrepreneurs have a stronger prior intuition. Also note that both entrepreneurs and managers are underrepresented in this class, given 
that on average they decide slower than employees do (e.g. $20 \%$ of the entrepreneurs fall within this class, while $25 \%$ would logically result if response time and occupation were independent). For the slowest $25 \%$ opposite results are found. Here entrepreneurs and managers are overrepresented and both make more contemplative choices than employees do (the $p$-value for the comparison between entrepreneurs and employees in this class equals $p=0.057)$.

Table 5 Differences in CI scores between Occupational Groups controlling for Response Time

\begin{tabular}{|c|c|c|c|c|}
\hline & \multicolumn{3}{|c|}{ Response Time class } & \multirow{2}{*}{$\begin{array}{c}\mathrm{p} \text { value of } \\
\text { ANOVA test }\end{array}$} \\
\hline & Quickest $25 \%$ & Intermediate $25-75 \%$ & Slowest $25 \%$ & \\
\hline \multirow[t]{2}{*}{ Entrepreneurs $(n=696)$} & $0.67^{\mathrm{b}}$ & $0.74^{\mathrm{b}}$ & 1.14 & $<0.01$ \\
\hline & $20 \%$ & $53 \%$ & $28 \%$ & \\
\hline \multirow[t]{2}{*}{ Managers $(n=265)$} & $0.94^{\mathrm{b}}$ & $0.96 \mathrm{~b}, \mathrm{c}$ & $1.25^{\mathrm{c}}$ & 0.05 \\
\hline & $18 \%$ & $53 \%$ & $29 \%$ & \\
\hline \multirow[t]{2}{*}{ Employees $(n=967)$} & 0.80 & $0.80^{\mathrm{c}}$ & $0.98^{\mathrm{c}}$ & 0.03 \\
\hline & $31 \%$ & $47 \%$ & $22 \%$ & \\
\hline \multirow[t]{2}{*}{ All $(n=1928)$} & 0.78 & 0.80 & 1.09 & $<0.01$ \\
\hline & $25 \%$ & $50 \%$ & $25 \%$ & \\
\hline
\end{tabular}

Notes: Letter subscripts indicate significant differences between two occopational groups at the $5 \%$ level using a two sided t- test (a for entrepreneurs versus employees, b for entrepreneurs versus managers, and c for managers versus employees). The final column reports the p-value of an ANOVA test comparing all three response time classes at the same time.

Another observation from Table 5 is that the effect of taking more time to think one's choices over seems larger for entrpreneurs as compared to (especially) employees. We further explore this in our earlier ordered Probit regression framework explaining the CI score. Taking column (1b) in Table 4 as a starting point, we add Response Time (scaled to units of 100 seconds) and its interactions with the two respective occupational dummies "Entrepreneur" and "Manager" as additional regressors. ${ }^{9}$ Column (1) in Table 6 reports the results. We indeed observe that the "Entrepreneur" dummy is signicantly negative, again pointing at entrepreneurs having a stronger intuitive prior. The interaction terms between Response Time and the two occupational dummies are signicantly positive, revealing that entrepreneurs and managers become relatively more contemplative over time than employees. They however do not differ in this respect from each other ( $p$-value is 0.84 ).

Because entrepreneurs and managers vary in a number of background characteristics from employees, the observed different effect of taking more time may potentially be driven by these. A first plausible conjecture is that especially the higher educated are more likely to deviate from making

\footnotetext{
${ }^{9}$ Table 5 suggests that the effect of response time might be non-linear. Including a quadratic term of Response Time (and interactions with other explanatory variables) does not yield significant coefficients though.
} 
the a priori intuitive choice when they take more time to carefully think about the decision. Column (2) explores this potential explanation. Instead of interaction terms with occupation, it includes the interaction between Response Time and Education. This interaction appears to be insignificant, hence we cannot conclude that higher educated participants are relatively more contemplative per unit of time. A similar explanation could be that, instead of education, it is rather those participants with a higher Need for Cognition or a higher Faith in Intuition who are different. Column (3) reports the results when these explanatory variables and their interactions with Response Time are included. Those with a higher Need for Cognition appear to be relatively more contemplative per unit of time; the interaction with Response Time is signicantly positive. For Faith in Intuition we do not find an effect. In the final specification of Column (4) we therefore include both the interactions with occupation and the interaction with NFC. We find that all these interaction terms remain significant and of similar size. Altogether, Table 6 suggests that entrepreneurs, managers and employees differ in their prior intuition as well as in the inclination to and the effect of taking more time. 
Table 6 Additional Ordered Probit Regressions explaining the CI scores

\begin{tabular}{|c|c|c|c|c|}
\hline & (1) & (2) & (3) & (4) \\
\hline Dependent variable: & $\mathrm{CI}$ & $\mathrm{CI}$ & $\mathrm{CI}$ & $\mathrm{CI}$ \\
\hline \multirow[t]{2}{*}{ Entrepreneur } & $-0.209^{* *}$ & -0.032 & -0.030 & $-0.227^{* *}$ \\
\hline & {$[0.100]$} & {$[0.059]$} & {$[0.060]$} & {$[0.100]$} \\
\hline \multirow[t]{2}{*}{ Manager } & 0.020 & $0.196^{* *}$ & $0.193^{* *}$ & 0.025 \\
\hline & {$[0.147]$} & {$[0.082]$} & {$[0.083]$} & {$[0.146]$} \\
\hline \multirow[t]{2}{*}{ Response Time / 100} & $0.057^{*}$ & -0.191 & 0.006 & $-0.253^{* *}$ \\
\hline & {$[0.031]$} & {$[0.091]$} & {$[0.153]$} & {$[0.103]$} \\
\hline \multirow[t]{2}{*}{ Entrepreneur x Response Time / 100} & $0.083^{* *}$ & & & $0.094^{* *}$ \\
\hline & {$[0.040]$} & & & {$[0.039]$} \\
\hline \multirow[t]{2}{*}{ Manager x Response Time / 100} & $0.083^{*}$ & & & 0.079 \\
\hline & {$[0.057]$} & & & {$[0.056]$} \\
\hline \multirow[t]{2}{*}{ Education x Response Time / 100} & & 0.041 & & \\
\hline & & {$[0.028]$} & & \\
\hline \multirow[t]{2}{*}{ Faith in Intuition (FI) } & & & 0.012 & \\
\hline & & & {$[0.017]$} & \\
\hline \multirow[t]{2}{*}{ Need for Cognition (NFC) } & & & -0.022 & -0.022 \\
\hline & & & {$[0.014]$} & {$[0.014]$} \\
\hline \multirow[t]{2}{*}{ Faith in Intuition x Response Time / 100} & & & -0.011 & \\
\hline & & & {$[0.017]$} & \\
\hline \multirow[t]{2}{*}{ Need for Cognition x Response Time / 100} & & & $0.016^{* * *}$ & $0.017^{* * *}$ \\
\hline & & & {$[0.005]$} & {$[0.06]$} \\
\hline Control variables & YES & YES & YES & YES \\
\hline Obs. & 1,928 & 1,928 & 1,928 & 1,928 \\
\hline Log lik. & $-2,187$ & $-2,187$ & $-2,183$ & $-2,182$ \\
\hline $\mathrm{ENT}=\mathrm{MAN}$ & 0.11 & $<0.01$ & $<0.01$ & 0.08 \\
\hline $\mathrm{ENT} \times \mathrm{RT}=\mathrm{MAN} \times \mathrm{RT}$ & 1.00 & & & 0.79 \\
\hline
\end{tabular}

Notes: Significance at the $10 \%$ level is denoted by $*, 5 \%$ by **, and $1 \%$ by ***, with robust standard errors reported in square brackets. The next to final row reports the p-value of a Wald test that 'Entrepreneur' = 'Manager', the final row the p-value of a Wald test for the interaction terms with response time.

\section{Conclusion}

Decision-making styles have been of interest to economists and psychologists alike. Most studies in psychology have relied on the Faith in Intuition and Need for Cognition self-assessment scales. Economists in general favor more 'objective' measures based on actual decision behavior (cf. Holm et al. $(2016,2013))$. In a recent stream of work Rubinstein $(2007,2013,2016)$ uses response times to classify action choices in strategic games as either instinctive or contemplative. "Fast actions" are considered instintive while "slow actions" are seen as more contemplative. 
In this paper we use both approaches in examining whether entrepreneurs have a different decision making style than other occupational groups do. Our final sample consists of 696 established entrepreneurs, 265 managers, and 967 employees (hence $n=1,928$ ). The results on the objective measures show that entrepreneurs make more intuitive choices than managers, but not than employees. At the same time entrepreneurs take about equal time as managers and more time than employees. For the subjective measures we find that entrepreneurs score highest on Faith in Intuition, while managers score highest on Need for Cognition. To reconcile the mixed findings on the objective measures, we run an addtitional set of regressions to explore the relationship between choosing contemplative actions and individual response time. We find suggestive evidence that entrepreneurs start from a stronger intuitive prior, but share with managers that they take more time to think and are also more effective with their time invested (compared to employees).

As our study is descriptive in nature, our study cannot disentangle personality traits (i.e. 'nature') from environmental effects (i.e. 'nurture'). That is, it could be that the uncertain environments that entrepreneurs are typically facing trigger more intuitive decision-making (cf. Busenitz and Barney, 1997). Alternatively, if there is a predominance of one of the two decision-making styles, as suggested by Kahneman (2011, p. 48), our findings could be the result of different types sorting into different occupations with different skill requirements. Disentangling this seems a promising avenue for future research.

\section{References}

Burmeister, K., C. Schade. 2007. Are entrepreneurs' decisions more biased? An experimental investigation of the susceptibility to status quo bias. Journal of Business Venturing 22(3) pp. 340-362.

Busenitz, L.W., J.B. Barney. 1997. Differences between entrepreneurs and managers in large organizations: Biases and heuristics in strategic decision-making. Journal of Business Venturing 12 pp. 9-30.

Cappelen, A.W., U.H. Nielsen, B. Tungodden, J.R. Tyran, E. Wengstrom. 2016. Fairness is intuitive. Experimental Economics 19 pp. 727-740.

Choi, S., S. Kariv, W. Müller, D. Silverman. 2014. Who is (more) rational? American Economic Review 104(6) pp. 1518-1550.

Epstein, S. 2003. Cognitive-experiential self-theory of personality, chap. in T. Millon and M.J. Lerner, eds., Comprehensive Handbook of Psychology, Volume 5: Personality and Social Psychology. Hoboken: Wiley and Sons, pp. 159-184.

Epstein, S., R. Pacini, V. Denes-Raj, H. Heier. 1996. Individual differences in intuitive-experiential and analytical-rational thinking styles. Journal of Personality and Social Psychology 71(2) pp. 390-405.

Evans, J.S.B.T. 2008. Dual-processing accounts of reasoning, judgment, and social cognition. Annual Review of Psychology 59 pp. 255-278.

Holm, H.J., V. Nee, S. Opper. 2016. Strategic decisions: Behavioral differences between CEOs and others. working paper . 
Holm, H.J., S. Opper, V. Nee. 2013. Entrepreneurs under uncertainty: An economic experiment in China. Management Science 59(7) pp. 1671-1687.

Hsu, D.K., S.A. Simmons, A.M. Wieland. 2017. Designing entrepreneurship experiments: A review, typology and research agenda. Organisational Research Methods 20 pp. 379-412.

Kahneman, D. 2011. Thinking, Fast and Slow. Farrar, Straus and Giroux, New York.

Koudstaal, M., R. Sloof, C.M. van Praag. 2016. Risk, uncertainty and entrepreneurship: Evidence from a large lab-in-the-field experiment. Management Science 62 pp. 2897-2915.

Kraus, S., F. Meier, Th. Niemand. 2016. Experimental methods in entrepreneurship research: The status quo. International Journal of Entrepreneurial Behavior and Research 22 pp. 958-983.

Rubinstein, A. 2007. Instinctive and Cognitive Reasoning: A Study of Response Times. The Economic Journal 117 pp. 1243-1259.

Rubinstein, A. 2013. Response time and decision making: A "free" experimental study. Judgment and Decision Making 8 pp. 540-551.

Rubinstein, A. 2016. A typology of players: between instinctive and contemplative. Quarterly Journal of Economics 131 pp. 859-890.

Shepherd, D.A., T.A. Williams, Patzelt H. 2015. Thinking about entrepreneurial decision making: Review and research agenda. Journal of Management 41 pp. 11-46. 